\title{
CULTURAL HERITAGE DOCUMENTATION AND INTEGRATED GEOMATICS TECHNIQUES IN AN EDUCATIONAL CONTEXT: CASE BOIS-DU-LUC (BELGIUM)
}

\author{
C. Stal ${ }^{\text {a, * }}$, R. Goossens ${ }^{\text {a }}$, L. Carlier ${ }^{\text {a }}$, J. Debie ${ }^{\text {a,b }}$, K. Haoudy ${ }^{\text {c }}$, T. Nuttens ${ }^{\text {a }}$, A. De Wulf ${ }^{\text {a }}$ \\ a Department of Geography, Ghent University, Ghent, Belgium - (Cornelis.Stal, Rudi.Goossens, Leen.Carlier, \\ Jacques.Debie, Timothy.Nuttens, Alain.DeWulf)@UGent.be \\ ${ }^{\mathrm{b}}$ Service Public de Wallonie, Namur, Belgium \\ ${ }^{c}$ Ecomusée du Bois-du-Luc (World heritage site), La Louvière, Belgium - karima.haoudy@gmail.com
}

KEY WORDS: UNESCO World Heritage, geomatics, topography, education, Bois-du-Luc, mining site, industrial heritage

\begin{abstract}
:
The Walloon Region in Belgium played a leading role in the world economy and in the industrial sciences and engineering since the $19^{\text {th }}$ century. Several relicts, such as important industrial buildings or sites, are spread over a large area and are still dominating the current landscape. Some of these remnants are preserved as monuments, representing the industrial, cultural and ecological transition of the region during the last two centuries. Since 2012, UNESCO recognized the importance of four of the best preserved $19^{\text {th }}$ and $20^{\text {th }}$ century coal mining sites and classified them as World Heritage ("Major Mining Sites of Wallonia", Le Grand-Hornu, Bois-duLuc, Le Bois du Cazier and Blegny Mine). The four recognised mining sites together form a strip of about $170 \mathrm{~km}$ long, containing important examples of the so-called 'neo classical architecture' from the early periods of the industrial era in continental Europe. Motivated by this recognition and by the huge touristic and educational potential of the sites, a partnership between the Walloon government and Ghent University was organized. In this first stage, the collaboration focuses on the site of Bois-du-Luc in the municipality of La Louvière, containing a large series of dwellings, several equipments built between 1853 and 1923 by the Société des Charbonnages du Bois-du-Luc, workshops and heaps. Consisting of numerous buildings dating back to the period between 1838 and 1923, this site is one of Europe's oldest collieries.

The collaboration between the Walloon government and Ghent University - Department of Geography fits in the hands-on training which students in land surveying and geomatics receive during their Bachelor studies. For the students it is very interesting that their practical exercises are not limited to the university campus, but that they are involved in a real measurement campaign. The project consists of a series of intensive land surveying campaigns, resulting in highly detailed and accurate maps of the site, including the inside domain of the buildings. Already available aerial photographs are processed to obtain a 3D model of the site and the wider region. In March 2013, the first campaign took place. During this first campaign, a topographical network was set out and a series of detail points were measured for the detailed topographic mapping. The topographical network was well-planned and covers almost the whole site, forming a set of permanently materialized reference points for later measurements. Besides, a large number of ground control points (GCPs) were taken for the 3D reconstruction of the area, based on high resolution airborne imagery. This enables the students to familiarize themselves with photogrammetric principles in a practical exercise. Both the topographic maps and the 3D model fit within the large scale geographic reference map of the Walloon Region.

In this contribution, the results of this intensive trans-regional collaboration on the preservation of the sites are presented. This paper will discuss the first deliverables from the project and the advantages for the responsible government, the cultural heritage organisations (Ecomusée du Bois-du-Luc) and the students. The main focus here is on the educational context of the project. Furthermore, future projects on the same site will be discussed.
\end{abstract}

\section{INTRODUCTION}

The academic degree of land surveyor was introduced at Ghent University in 1990, as a 4-year program and as an option of the program of geography. The original program has been converted into a 5-year curriculum, in accordance with the BAMA revolution of 2005. The 'Master in Geomatics and Surveying' is currently the only academic program of its kind in Flanders, with a Wallonian counterpart of the degree of 'Master in Geography, option Geomatics and Geometrology' at the University of Liège.

The Geomatics program at Ghent University focusses on three pillars, namely data acquisition, geographic information management and real estate. This focus is stressed out in the reformed program of 2011 (De Wulf et al., 2011b), in accordance with the definition of 'Geomatics' according to the Canadian Institute of Geomatics. Here, Geomatics is defined as 'a field of activities which, using a systematic approach, integrates all the means used to acquire and manage spatial data required as part of scientific, administrative, legal and technical operations involved in the process of the production and management of spatial data' (http://www.cig-acsg.ca). As a result, a surveyor has to focus on the analysis, management and communication of spatial data, next to the sole acquisition of them.

Next to fundamental education in the field of Geomatics, more practical training and project work will be implemented for the students (De Wulf et al., 2013). One of these projects is

\footnotetext{
* Corresponding author.
} 
organized in an international context as part of an Erasmus Intensive Training Program, recognized and sponsored by the European Commission (De Wulf et al., 2012). The academic bachelor program in geomatics of Ghent University is organized as an option of the program in Geography. In the first year of the program, the difference between both options is nonexistent, in the second year circa half of the program is different, in the third year almost all courses are different. Typical geomatics subjects as Topometry, Photogrammetry, Cartography, Law are therefore studied in the third year. An outcome to the professional market after the "Bachelor Geography and Geomatics - Main Subject: Geomatics" is theoretically possible, although almost all students continue their studies with a "Master" study, mostly the "Master in Geomatics and Surveying".

This paper covers the practical exercises of two different courses of the third bachelor, namely Topometry (I and II) and the Integrated Exercise Geomatics. Each year, an intensive internship is organized, where student can practice their skills in topography on the field, as part of the course Topometry. Previous campaigns were organized in the area of the Kemmelberg, Belgium, because of the archaeological potential of the area (Stal et al., 2011). Up to this year, the Integrated Exercise Geomatics, which is another course, was organized on the campus of the Faculty of Sciences. This year the field work is integrated, since most students who take the course Topometry also take the Integrated Exercise Geomatics, thanks to a trans-regional collaboration between Ghent University, the Walloon government and the cultural heritage organisation of the Ecomusée du Bois-du-Luc. The results of the student's field work assist with the management and preservation of the UNESCO world heritage site of Bois-du-Luc. A short overview of this site is presented in section two. In section three, an overview of the courses Integrated Exercises Geomatics and Topometry is discussed, followed by the presentation of the first results. The paper is finalized by a brief formulation of the conclusions.

\section{SITUATION: BOIS-DU-LUC}

Bois-du-Luc is an old mining site, situated in the Walloon 'Central Bassin - Bassin du Centre' near La Louvière. This basin is located between the 'Borinage' near Mons and the basin of Charleroi. Several characteristic soil tips ("Terril") in the neighborhood are silent witnesses of the industrial past of the area (Figure 1).

The Société des Charbonnages du Bois-du-Luc was founded in 1685 and closed its last pits in Trivières (Le Quesnoy) in 1973. In 1846, the Société des Charbonnages du Bois-du-Luc opens, in Bois-du-Luc, the pit Saint-Emmanuel, the actual pit that we can visit today. This pit forms the origin of the mining site which includes work places and a complete mining village.

The pit Saint-Emmanuel reached a depth of $558 \mathrm{~m}$ below the ground surface in 1959. The shaft is currently covered with a concrete slab. After the closure of the mine, the cultural potential of the site had soon been recognized, and in 1983, the Ecomuseum of Bois-du-Luc was founded in the former offices and workspaces of the site.

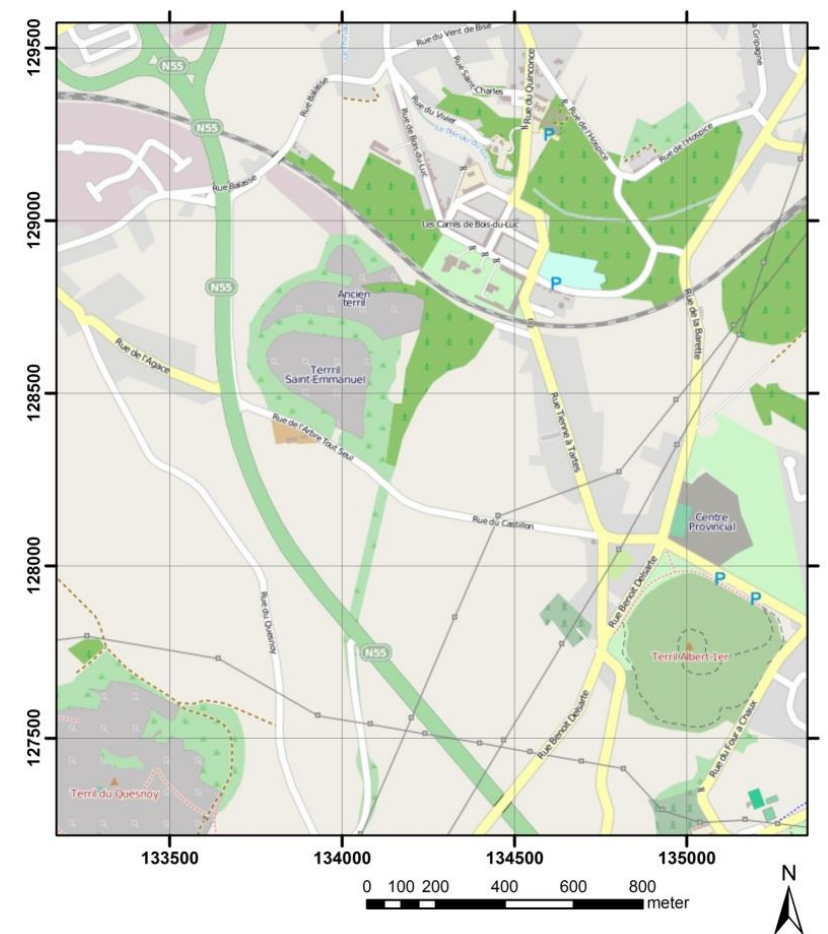

Figure 1: Topographic map of the Bois-du-Luc and its environment (source: OSM, grid in Belgian Lambert 72)

From 1838 to 1853 , 166 living quarters were built for the housing of the workers, as commissioned by the mining management in order to attract and attach the workers (Figure 2). Moreover, a separated living quarter was built in 1844 for the general director (Figure 3), as well as a grocery, butcher and "glacière", party hall, park and its kiosk, church, schools, library, hospice, hospital, school, houses for employees and engineer, mill brewery. Bois-du-Luc is an illustration of an exemplary conservation of the paternalistic ideology. In 2012, the entire mining site of Bois-du-Luc was recognized as World heritage by UNESCO, next to three other important mining sites in the Wallonia.

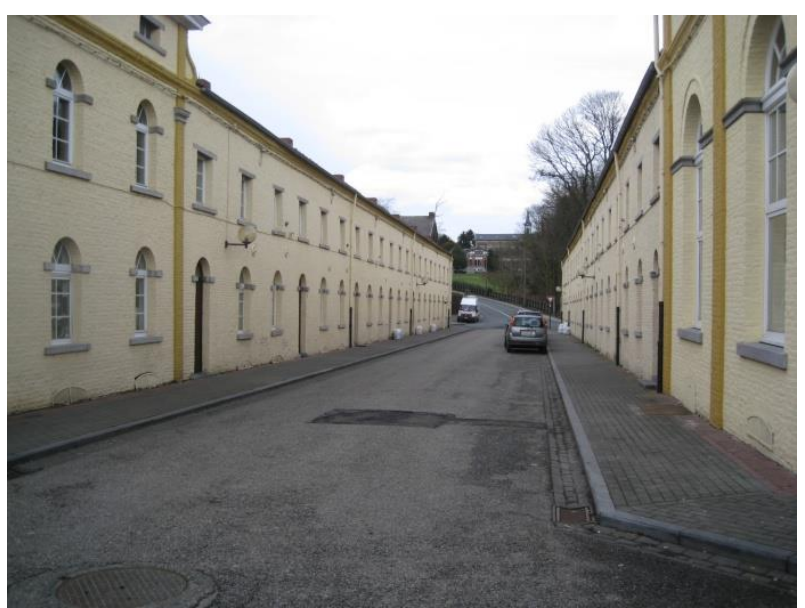

Figure 2: Workers quarters at Bois-du-Luc with the church St Barbara, the hospital, the school for the girls, the hospice, the houses for the engineer and employees, the park with its kiosk, the butcher and "glacière" and school for the boys and the library on the background 


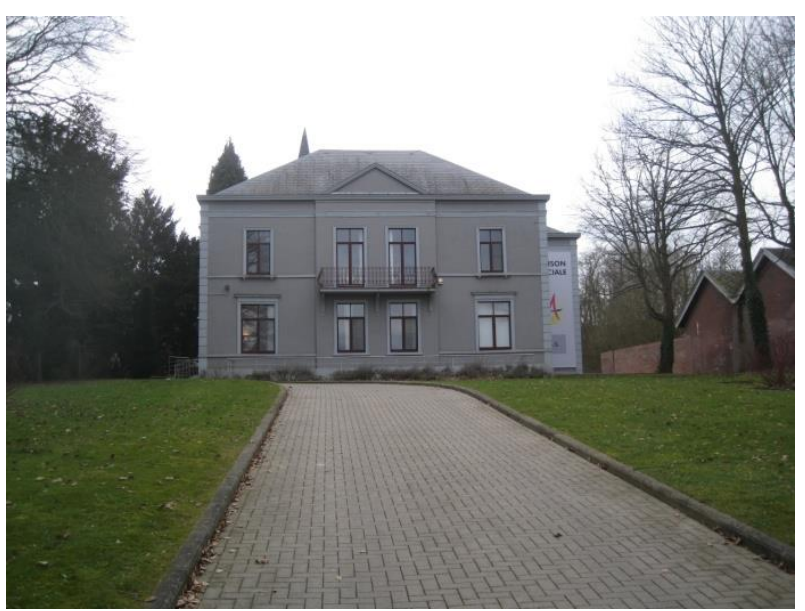

Figure 3: House of the general director (1844)

\section{STUDENT PARTICIPATION ADMITTANCE}

Students of the third bachelor year in 'Geography and Geomatics, option Land Surveying' of the Department of Geography, Ghent University, will participate in the project following the courses 'Integrated Exercises Geomatics' and 'Topometry', representing 4 and 5 ETCS credits respectively, and covering the two different aspects of the campaign. During the campaign, the students are supposed to perform most of the work by themselves, but assistance of university staff is provided.

\subsection{Integrated Exercises Geomatics}

The goal of the Integrated Exercise Geomatics course is to provide students with insights in the integrated approaches for case studies on the measurement, processing and visualization of geometrical objects. Prior knowledge of the basics of geomatics and topography are required. During the course, different concepts dealing with the integrated production of spatial 3D data are discussed. The project at the site of Bois-duLuc enables the students to apply their knowledge about topographic equipment, processing software for topographic measurements and photogrammetry, as well as Computer Assisted Design (CAD), Geographic Information Systems (GIS) and cartography. After finalizing this course, the students will be able to solve the integrated case study, containing topographic measurements, processing and visualization of different 3D objects on the field (http://studiegids.ugent.be). In this exercise, the geometry of the problem is reduced to a $2.5 \mathrm{D}$ approach: an airborne orthophoto and Digital Elevation Model (DEM) have to be calculated, using conventional digital photogrammetry. Besides, a series of buildings has to be measured in detail and a CAD model has to be constructed using solid geometries. The final product is an integrated visualization with appropriate rendering parameters. After succeeding this course, the students will be able to follow the course '3D Registration and Visualization', where students will focus on more advanced 3D data acquisition and processing, as well as on quality assessment (Nuttens et al., 2011b). The current exercise for this course is organized in the city of Ghent, with a special focus on terrestrial laser scanning, terrestrial photogrammetry and structure from motion multi view stereo (Nuttens et al., 2011a; Stal et al., 2012).

\subsection{Topometry I and II}

During the courses Topometry I and Topometry II, the students learn the insights of planimetric and altimetric land surveying methods. The accuracy of different instruments and methods, like intersection or resection using a total station, are also discussed. Lectures about the accuracy of topographic instruments and practical sessions on this topic are illustrated by a calibration bench (De Wulf et al., 2011a). Different kinds of triangulation and trilateration networks with various adjustment methods are also presented. Finally, the principles of staking out an Euler spiral or arcs will be learned. In the second part of this course (Topometry II), the students learn how to perform detail measurements in accordance with the criteria of the Flemish statewide large scale reference map (GRB). The field campaign discussed in this paper was originally part of this course, only focusing on topographic measurements.

This course is one of the basic ones of the bachelor program and requires some introductory knowledge about topography and Geomatics. After positive evaluation, the student fulfills the educational requirements of the governmental criteria of an official land surveyor, with a special focus on the traditional surveying methods. The student will be able to perform topographic tasks (measuring projects) independently, including the adjustments, visualization and quality assessment.

\section{FIRST RESULTS}

\subsection{Integrated Exercise Geomatics}

In order to perform the exercise, a stereo couple is supplied by the Walloon Region. Reference points and ground control points are measured using RTK GNSS and the WALCORS reference network with centimeter accuracy. The coordinates of both materialized polygon points and unambiguous image points are defined in the Belgian Lambert 72 system. Initially, at least twelve ground control points have to be measured by the students. These points, as well as the calibration parameters of the images, are processed using professional photogrammetric software. This process results in an orthophoto and DEM of the site. A screenshot of the orthophoto is presented in Figure 4.

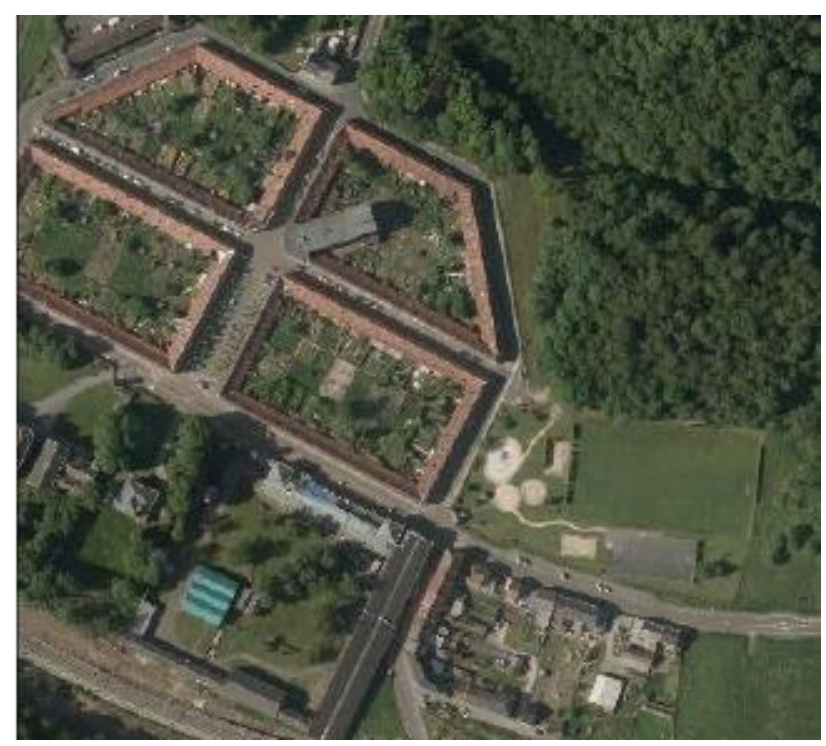

Figure 4: Screenshot of one of the generated orthophotos

A series of topographic measurements is also performed on some of the workers residences. The coordinates of the roof 
ridge, some windows and doors as well as the general outline have to be measured, in addition to the lampposts in the direct neighborhood. A 3D reconstruction of these elements is generated in a $\mathrm{CAD}$ environment and rendering parameters are also defined for a night- and day visualization (Figure 5). The link between the orthophoto, the topographic measurements and DEM is very important for this exercise, as well as the relation between the different error sources and the visualization parameters.

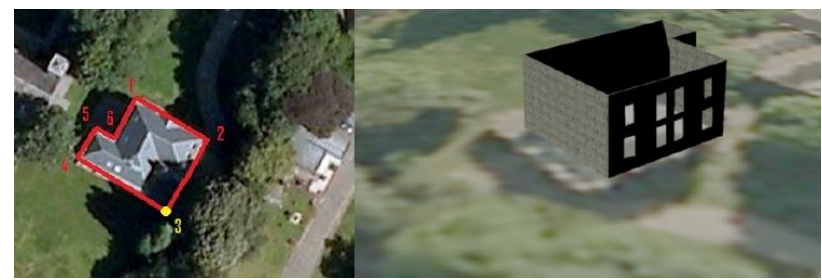

Figure 5: Screenshot of the 3D visualisation of a building

The results of the exercise have to be explained in a detailed report, as well as in an oral presentation. These should cover the used methods and results of the measurements, photogrammetric image processing and visualization of the buildings. A special focus in this report is given to the description and analysis of accuracies and errors.

\subsection{Topometry I and II}

During the entire exercise, the students have to perform topographic measurements to make a detailed map in accordance with the rules on topography and cartography. The plan must meet the requirements of the standardized ontology, appearance and other feature properties as defined by the Flemish government for the state wide and large scale mapping project. The map should contain all characteristic elements of the terrain, represented on a sufficiently large scale. Besides, the elevation of different terrain points, reference points of a polygon and of other substantial elements have to be presented in the map (Figure 6). Students also improve their skills in CAD-software by the integration of their own measurements with a scanned and georeferenced national topographic map, the addition of a list of coordinates and the construction and representation of isohypses on the map.

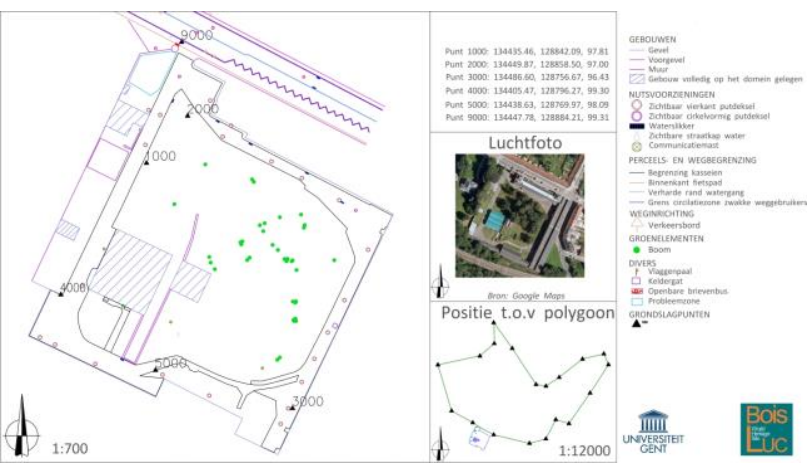

Figure 6: Representation of a measured situation map of the Ecomuseum

As such, for the students, this task is the first real confrontation with the different elements of the classical job of a land surveyor. Therefore, the students have to make a clear and detailed report on their activities, scientific background on the project and problems that occurred during the exercise, as well as the accompanying possible solutions.

\section{CONCLUSION AND LESSONS LEARNT}

As mentioned above, the students are evaluated by a various number of parameters. The ability of the student to demonstrate his or her thorough knowledge of the subjects is crucial. A critical review of the students themselves on cartographic details is also very important. Therefore, it is obvious that the students have to supply high quality and highly accurate deliverables, with detailed description of the processing procedures and quality assessment. These deliverables will be used as workable documents by the staff members of the site of Bois-du-Luc. The opinion of these cultural heritage experts is therefore indispensable for the evaluation of the products.

Based on the findings of the first year of the project, a fruitful continuation of the project is foreseen for the following years. The detailed topographic measurement, image based reconstruction and $3 \mathrm{D}$ modeling of the site of Bois-du-Luc is important for the managers of the site. For the following year, the project will be continued and the 3D model will be extended. Continuously communication with the site managers enables to let students work with 3D modeling and topography on objects with higher prioritiy. These tasks perfectly fit within the bachelor program of land surveying of Ghent University, which creates a win-win situation for all partners of the project.

\section{REFERENCES}

De Wulf, A., Constales, D., Meskens, J., Nuttens, T., Stal, C., 2011a. Procedure for analyzing geometrical characteristics of an EDM calibration bench, FIG Working Week, Marrakech, Morocco, pp. 14 (on CD-ROM)

De Wulf, A., Nuttens, T., Stal, C., De Maeyer, P., 2011 b. Evaluation and reformation (2011) of the geomatics education programs at Belgian academic universities, INTED2011 Conference, Valencia, Spain, pp. 3183-3192

De Wulf, A., Nuttens, T., Stal, C., De Wit, B., Seube, N., Boder, V., 2012. Erasmus Intensive Program (2011-2013) in Hydrography and Geomatics, FIG Working Week, Rome, Italy, pp. 10 (on CD-ROM)

De Wulf, A., Nuttens, T., Stal, C., Deruyter, G., 2013. Renewed (2013) geomatics bachelor, master and $\mathrm{PhD}$ programs at Belgian academic universities, SGEM, Albena, Bulgaria, pp. 8 (on CD-ROM)

Nuttens, T., De Maeyer, P., De Wulf, A., Goossens, R., Stal, C., 2011a. Comparison of 3D accuracy of terrestrial laser scanning and digital photogrammetry: an archaeological case study, in: Hamounová, L. (Ed.), 31th EARSeL symposium : Remote sensing and geoinformation not only for scientific cooperation, Prague, Czech Republic, pp. 54-65

Nuttens, T., De Maeyer, P., De Wulf, A., Goossens, R., Stal, C., 2011b. Terrestrial laser scanning and digital photogrammetry for cultural heritage: an accuracy assessment, FIG Working Week 2011, Marrakech, Morocco, pp. 10 (on CD-ROM)

Stal, C., De Wulf, A., De Maeyer, P., Goossens, R., Nuttens, T., 2012. Evaluation of the accuracy of 3D data acquisition techniques for the documentation of cultural heritage, 3rd EARSeL Workshop on Remote Sensing for Archaeology, Ghent, Belgium, pp. 8 (on CD-ROM) 
Stal, C., Nuttens, T., Bourgeois, J., Carlier, L., De Maeyer, P., De Wulf, A., 2011. Accuracy assessment of a LiDAR digital terrain model by using RTK GPS and total station. EARSeL eProceedings 10 (1), 1-8. 